This item was submitted to Loughborough's Research Repository by the author.

Items in Figshare are protected by copyright, with all rights reserved, unless otherwise indicated.

\title{
Analysis of fracture processes in cortical bone tissue
}

PLEASE CITE THE PUBLISHED VERSION

http://dx.doi.org/10.1016/j.engfracmech.2012.11.020

PUBLISHER

(c) Elsevier

VERSION

AM (Accepted Manuscript)

LICENCE

CC BY-NC-ND 4.0

REPOSITORY RECORD

Li, Simin, Adel A. Abdel-Wahab, and Vadim V. Silberschmidt. 2019. "Analysis of Fracture Processes in Cortical Bone Tissue". figshare. https://hdl.handle.net/2134/13131. 
This item was submitted to Loughborough's Institutional Repository (https://dspace.lboro.ac.uk/) by the author and is made available under the following Creative Commons Licence conditions.

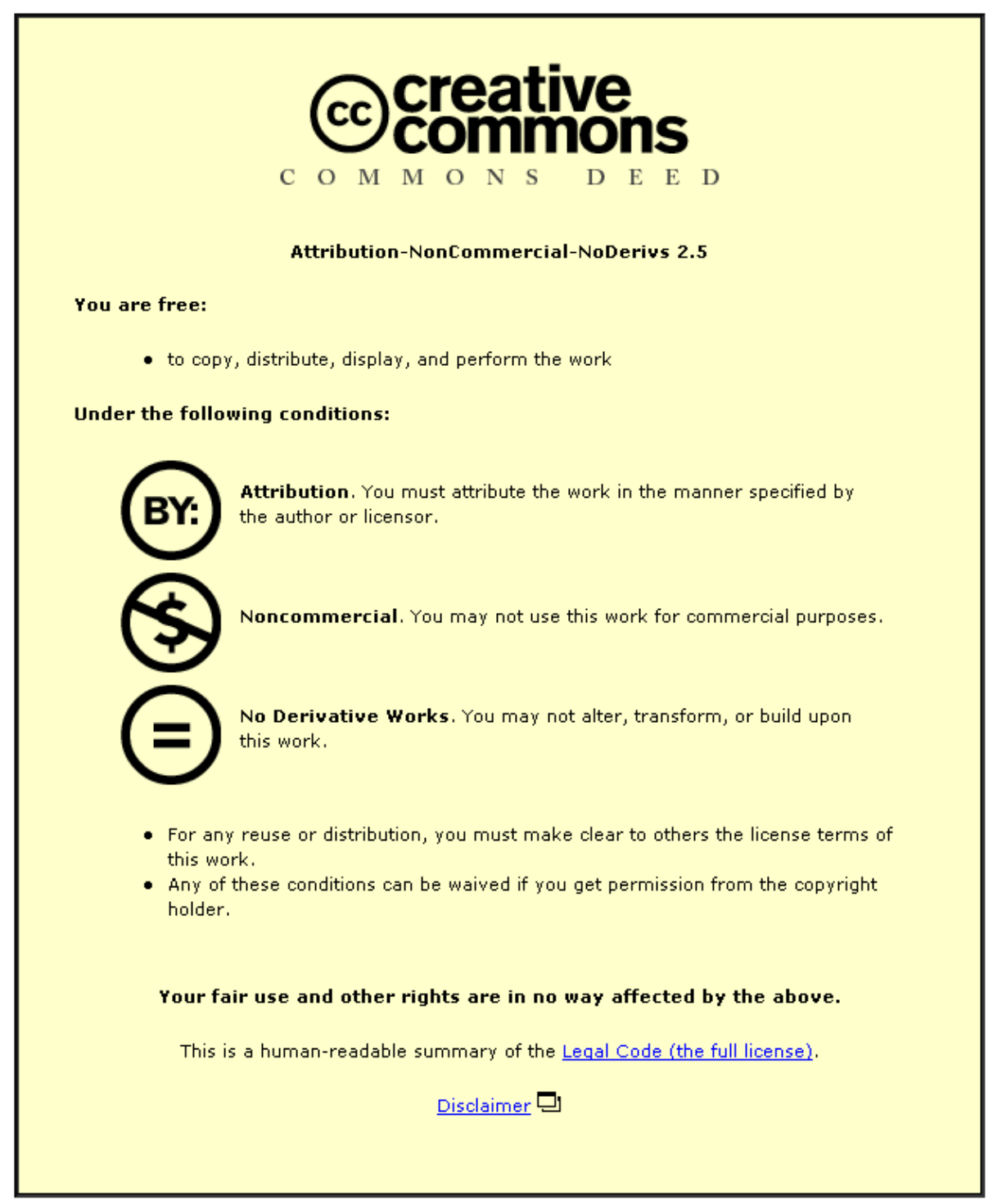

For the full text of this licence, please go to: http://creativecommons.org/licenses/by-nc-nd/2.5/ 


\title{
Analysis of fracture processes in cortical bone tissue
}

\author{
Simin $\mathrm{Li}^{1}$, Adel Abdel-Wahab ${ }^{2}$ and Vadim V. Silberschmidt ${ }^{3^{*}}$ \\ Wolfson School of Mechanical and Manufacturing Engineering, Loughborough \\ University, Loughborough, Leicestershire, LE11 3TU, UK \\ ${ }^{1}$ S.Li@lboro.ac.uk, ${ }^{2}$ a.a.abdel-wahab@lboro.ac.uk, ${ }^{3 *}$ V.silberschmidt@lboro.ac.uk
}

\begin{abstract}
Bones are the principal structural components of a skeleton; they play unique roles in the body providing its shape maintenance, protection of internal organs and transmission of forces. Ultimately, their structural integrity is vital for the quality of life. Unfortunately, bones can only sustain loads until a certain limit, beyond which they fail. Understanding a fracture behaviour of bone is necessary for prevention and diagnosis of trauma; this can be achieved by studying mechanical properties of bone, such as its fracture toughness. Generally, most of bone fractures occur in long bones consisting mostly of cortical bone tissue. Therefore, in this paper, an experimental study and numerical simulations of fracture processes in a bovine femoral cortical bone tissue were considered. A set of experiments was conducted to characterise fracture toughness of the bone tissue in order to gain basic understanding of spatial variability and anisotropy of its resistance to fracture and its link to an underlying microstructure. The data was obtained using single-edge-notch-bending specimens of cortical bone tested in a three-point bending setup; fracture surfaces of specimens were studied using scanning electron microscopy. Based on the results of those experiments, a number of finite-element models were developed in order to analyse its deformation and fracture using the extended finite-element method (X-FEM). Experimental results of this study demonstrate both variability and anisotropy of fracture toughness of the cortical bone tissue; the developed models adequately reflected the experimental data.
\end{abstract}

Keywords: Fracture toughness; Cortical bone; Extended Finite Element (X-FEM); Anisotropy; Variability; J-integral 


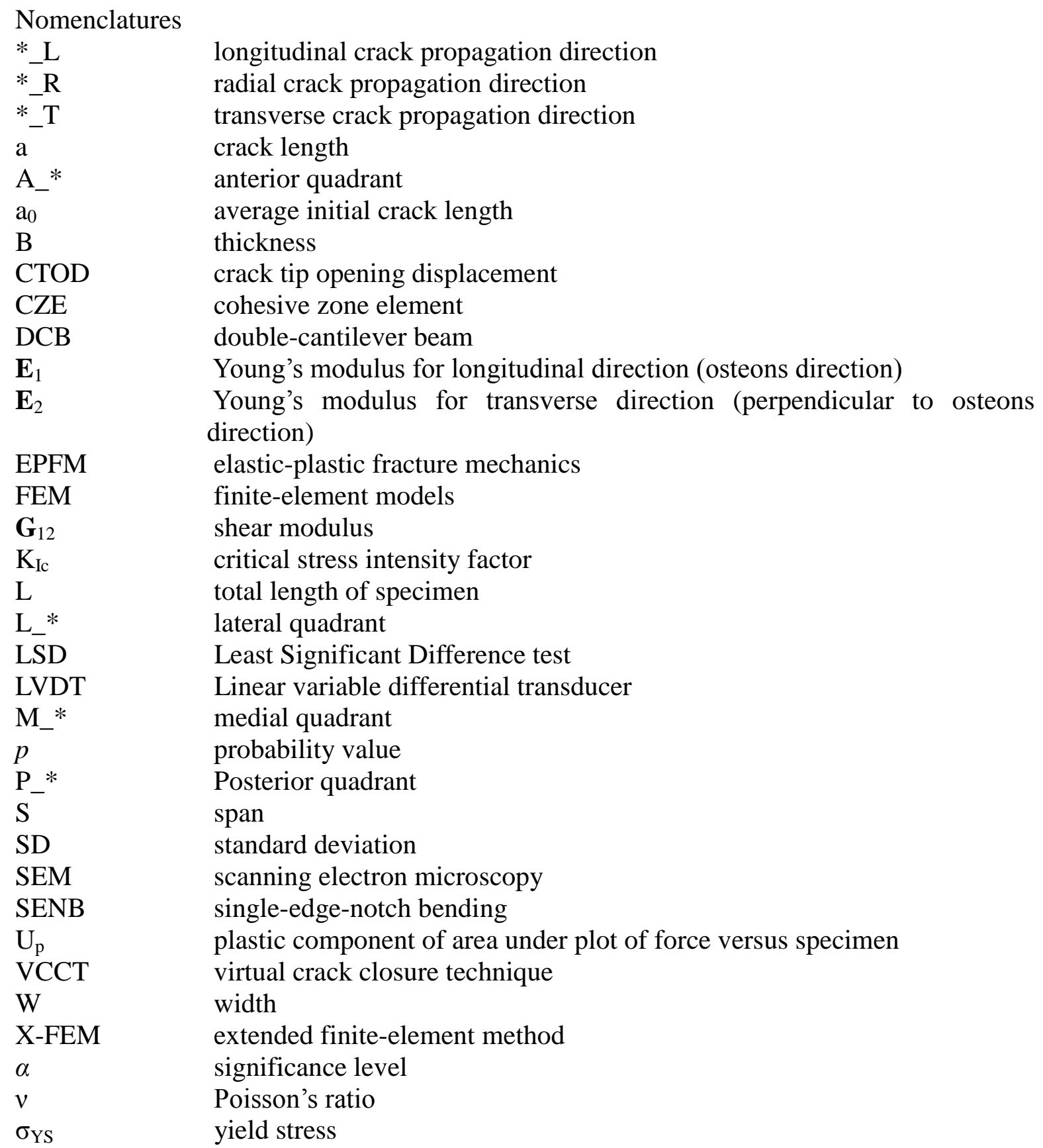




\section{Introduction}

Bone is a natural composite material with hierarchical organization at different length scales. At the nano-scale, it consists of a collagen matrix impregnated with ceramic nano-particles known as carbonated hydroxyapatite [1, 2]. At the micro-scale, cortical bone is in the form of lamellar layers of $5 \mu \mathrm{m}$ thickness. Similar to a plywood structure, inside a layer, collagen fibers are parallel; however, their orientations are different for different layers. Across a bone section, not all lamellae are arranged in the same way; for instance, near the outer and inner surfaces, lamellae are parallel and arranged along the cortical bone's circumference. On the other hand, the outside and inside circumferential lamellae form a region made of circular structures called osteons, formed from concentric lamellae within remnants of a bone's remodelling process called interstitial matrix. The interface between osteons and interstitial matrix is called cement line; it is a collagen-free and highly mineralized layer. Cement lines have an important effect on bone's behaviour, especially its fracture. Osteons are, on average, $200 \mu \mathrm{m}$ in diameter and $1 \mathrm{~cm}$ long and parallel to the bone's longitudinal axis [3]. In addition, a network of canals and channels is formed across the bone's section and along its axis; these canals accommodate blood vessels and called Haversian canals. Moreover, bone has living cells called osteocytes that live within an interconnected network of microscopic channels called canaliculi. The latter are responsible for exchange of nutrients and waste between osteocytes [3]. At the millimetre length scale, bone consists of a dense and thick outer layer called cortical bone and a sponge-like structure called trabecular bone [4]. All these hierarchical levels work together to enhance macroscopic mechanical properties of bone tissue at the full-bone scale [4].

Microarchitecture of the cortical bone tissue is complex and has a significant effect on its mechanical and fracture properties. Moreover, the preferential alignment of both collagen fibrils and nano-scaled mineral crystals causes anisotropy in both mechanical and fracture properties of the tissue [4]. Since in-vivo fractures are often initiated and/or promoted by cracks, fracture mechanics is considered an important tool in assessing bone tissue's integrity. Therefore, it can be used to enhance the diagnoses and treatment of bone fractures [5]. From a fracture toughness perspective, the cortical bone tissue has different fracture resistance for various crack-propagation directions relative to the long bone axis, i.e. it demonstrates 
fracture-toughness anisotropy. Various toughening mechanisms were reported for the cortical bone tissue including microcracks in the vicinity of the main crack due to stress concentrations ahead of its tip [6-8], and crack deflection and blunting at cement lines that are weak interfaces at the boundaries of secondary osteons [9]. Recently, it was reported that ligament bridging of crack in the wake zone is a dominant toughening mechanism in cortical bone as it reduces a driving force at the crack tip [10-12]. Several authors reported that toughening mechanisms are highly dependent on a crack propagation direction; therefore, fracture toughness of long bones is significantly higher in transverse and radial directions compared to the longitudinal one [12-14].

From a point of view of numerical simulations, a limited number of numerical models were reported in literature studying initiation and propagation of cracks in cortical bone. For instance, Ural and Vashishth [15] developed a cohesive-zone-element model in order to capture an experimentally observed rising crack growth behaviour and age-related loss of bone toughness. Later, the same authors used their previous model to investigate the effects of age-related changes and orientation of crack growth on a toughening behaviour of human cortical bone. In addition, the model was used to investigate changes in the anisotropy of toughening mechanisms with age. The used approach - cohesive-zone elements - has an inherent drawback: the crack-extension path must be predefined. Obviously, this is not the case in fracture of real bones, where a real crack path is hard to predict. Recently Morais et al. [16] demonstrated adequacy of a Double-Cantilever-Beam (DCB) test for determining fracture toughness under pure mode-I loading of cortical bone by implementing a new data-reduction scheme based on specimen's compliance and an equivalent crack concept. The used method helped to overcome the crack-monitoring difficulty during growth. A cohesive-zone model was used in that study to simulate damage initiation and propagation, thus assessing the used methodology. More recently, Ural et al. [17] used cohesive finite-element modelling to evaluate the effect of strain rate on both initiation and propagation toughness for human cortical bone. In addition, three-dimensional models based on micro-computed-tomography data for compact tension specimens were used to assess the effect of strain rate and porosity. Though the authors tried to model the fracture behaviour of the cortical bone tissue, still their models were based on the cohesive-element approach with its drawbacks 
mentioned earlier. A small number of papers studied fracture of bone at the macroscopic level using an extended finite-element method (X-FEM); for instance, Liu et al. [18] demonstrated how X-FEM can be used to predict proximal femur fracture due to impact. In addition, damage-initiation and -propagation parameters were assumed as a function of bone density. It was reported that no physical testing was performed to validate those simulation results.

Despite interest by many researchers to fracture toughness of the cortical bone tissue, understanding of the causes of bone fracture is still not fully developed. Therefore, in this paper, fracture toughness of cortical bone tissue was studied both experimentally and numerically, considering effects of both crack propagation direction and cortex position, to improve our understanding of the origins of its fracture resistance.

\section{Materials and Method}

\subsection{Specimen preparation}

The specimens in this study were cut from fresh bovine femora (age: 1.5-2 years). The mid-part of three femurs (diaphysis) was extracted using a fine-teeth band-saw. Then, the diaphysis part of each femur was sliced into four cortices - anterior, posterior, medial and lateral. Specimens for experiments were cut from each cortex in a way to allow studies of crack growth along three different orientations relative to bone axis - longitudinal, transverse and radial as shown in Fig. 1. After cutting, specimens were ground under tape water using a series of grinding papers Standard ANSI grit: 240,600 , and 1200 to make sure that the surface is clean, without any scratches or irregularities. After preparation, the test specimens were held in a $0.9 \%$ physiological saline solution until tested. All specimens were prepared with the same dimensions for comparison, according to the British Standard: BS 7448-1 [19]: 25 $\mathrm{mm} \times 2.72 \mathrm{~mm} \times 5.43 \mathrm{~mm}$ (total length $\times$ width $\times$ thickness). Also, a very fine slit with depth of $2.7 \mathrm{~mm}$ was produced using a low-speed diamond saw for all specimens according to British Standard [19]. In this paper, for simplicity, the specimens are labelled based on the crack propagation direction: longitudinal, transverse, or radial. Hence, specimens with crack propagating parallel to the bone axis is called longitudinal, perpendicular to it is called transverse and in the radial direction is called radial, see Fig. 1. Due to the geometrical constraints of the cortical bone 
tissue, and in order to cut specimens with comparable dimensions, specimens with maximum total length $(L=25 \mathrm{~mm}$ ) were used for all cortices and crack directions. Hence, span (S), width (W), thickness (B) and crack length (a) of specimens were chosen based on total length $25 \mathrm{~mm}$ and dimensions proportions using British Standard [19]. The used dimension proportions are $L=4.6 \mathrm{~W}, \mathrm{~S}=4 \mathrm{~W}, \mathrm{a} / \mathrm{W}=0.5$, and $B=W / 2$.

\subsection{Fracture toughness: measurements and calculations}

The fracture-toughness tests were performed using a single-edge-notch bending scheme on an Instron 3345 machine with a $5 \mathrm{kN}$ load cell. All specimens were loaded to failure with a displacement rate of $1 \mathrm{~mm} / \mathrm{min}$. Specimens were loaded in three-point bending with load measured and recorded using the machine's load cell and the corresponding load-line displacement was simultaneously measured using a linear variable differential transducer (LVDT), see Fig. 2. The obtained loaddisplacement curves were analysed according to the British Standard [19]. Notched specimens cut from the diaphysis part of bovine femur were tested in transverse, longitudinal and radial orientations for four cortex positions: anterior, lateral, posterior and medial. After tests, fracture surfaces of all the specimens were investigated using scanning electron microscopy (SEM). Since cortical bone is not a conductive material, specimens were air-dried and gold-coated before SEM investigation.

Plane-strain fracture toughness, $K_{\mathrm{lc}}$, a crack tip opening displacement (CTOD), or I values can be determined using the specimen's dimensions, depth of notch, $0.2 \%$ proof strength $\left(\sigma_{\mathrm{Ys}}\right)$ and specific data from the force-displacement record of the fracture test. When the type of fracture is elastic-plastic, it is not possible to determine a valid $K_{\mathrm{lc}}$ value to represent fracture toughness of a material. However, either critical CTOD or critical J values can be calculated. In this study, the behaviour of all specimens was predominantly non-elastic; therefore, an elastic-plastic fracture mechanics (EPFM) parameter, J-integral, was calculated based on British Standard BS 7448-1, using the following equation [19]:

$$
J=\left[\frac{F S}{B W^{1.5}} \times f\left(\frac{a_{0}}{W}\right)\right]^{2} \frac{\left(1-v^{2}\right)}{E}+\frac{2 U_{p}}{B\left(W-a_{0}\right)},
$$


where $\mathrm{S}$ is the bending span, $\mathrm{F}$ is the applied force, $\mathbf{f}\left(\frac{a_{0}}{W}\right)$ is a function of $\left(\frac{a_{0}}{W}\right), v$ is Poisson's ratio, $\mathrm{E}$ is elastic modulus, $\mathrm{U}_{\mathrm{p}}$ is the plastic part of area under plot of force versus specimen displacement along the load-line, $B$ is the specimen's thickness, $W$ is the effective width of the test specimen and $a_{0}$ is the average original crack length.

\subsection{Numerical Models of Three-Point-Bending Test}

Analysis of the actual crack initiation and growth is hard to achieve using approaches such as cohesive zone element (CZE) and virtual crack closer technique (VCCT) due to the well-known fact that in these schemes the crack path has to be defined in advance. However, with the Extended Finite-Element Method (X-FEM), a crackpropagation process can be modelled based on a solution-dependent criterion without introduction of a predefined path. Thus, the aim of this part of the study was to develop and validate numerical models using X-FEM for analysis of the deformation and fracture behaviour of the cortical bone tissue under a quasi-static loading regime of three-point bending. For our simulations, two groups with a total of eight finite-element models (FEM) were developed reproducing the three-point bending setup with quasi-static loading conditions used in our experiments: Group A and Group B for longitudinal and transverse cracks, respectively. Simulations were performed using X-FEM implemented into the finite-element software Abaqus $6.11 / \mathrm{Implicit}$. The geometry and dimensions of specimens in simulations are shown in Fig. 3. The diameters of modelled pin holders were $10 \mathrm{~mm}$. The following assumptions were made in the developed numerical models: (1) plain-strain conditions of the specimen; (2) elastic transverse orthotropic material properties for the bone specimens (see Table 1); (3) a friction coefficient of 0.3 was considered for interfaces between the pins and specimen.

In these simulations, damage initiation and evolution criterion employed a surfacebased cohesive traction-separation law based on the elastic-plastic fracture mechanics. The model determined damage based on a chosen fracture strain, which corresponded to maximum principal strain of $0.6 \%[22,23]$ in this case. When the fracture strain was reached, damage initiation started, and then, damage evolution took place. The evolution criterion was defined in terms of fracture energy (per unit area) and a linear damage softening response was chosen for the analysis. Crack 
follows an arbitrary, solution-dependent path in the balk material, and the path is independent of the element boundaries in the mesh. The fracture toughness obtained from the experimental part of this study was introduced into the developed $\mathrm{X}$-FEM models as fracture energy as shown in the results section. The initial notch was introduced as a $2.7 \mathrm{~mm}$-long straight line in the model, and the whole specimen was chosen as X-FEM enrichment area.

For Models A and B, a total number of 8600 linear quadrilateral (CPE4R) elements were used to generate a mesh for the simulated bone specimen. The fixtures of three-point bending were modelled as 2D analytical rigid shell, planar wire. A general contact with penalty friction formulation was defined between the bone specimen and these fixtures.

\section{Results}

\subsection{Elastic-plastic fracture mechanics}

Critical values of fracture toughness $J_{c}$ of the studied cortical bone tissue were calculated with respect to three crack-growth directions: longitudinal, radial and transverse; in addition, anisotropy ratios of the fracture toughness values were analysed. The obtained experimental data demonstrated that all specimens exhibited a non-linear elastic-plastic fracture process; hence, the J-integral was used to quantify the fracture toughness. Table 2 lists the average levels and standard deviation of critical values of $J$-integral and for all crack growth directions and for four cortices.

It can be noticed from these results that the fracture-toughness values for specimens cut from different cortices of bovine femur cortical bone are significantly different. In general, cortical bone shows higher resistance to fracture when a crack grows perpendicular to osteons (see Fig. 1) and lower resistance for the radial and longitudinal directions (i.e. with the fracture surfaces parallel to osteons). For a crack growing in transverse direction, specimens in the medial quadrant had the highest critical value of $\mathrm{J}$-integral while those for posterior specimens were the lowest. The Fisher's Least Significant Difference (LSD) test $(\alpha=0.05)$ found statistically significant differences between anterior to medial $(p=0.033)$, medial to posterior ( $p$ $=0.0025)$ and posterior to lateral $(p=0.0059)$ cortices. On the other hand, specimens with radially extended cracks were found to have the highest fracture 
toughness in case of the lateral quadrant and the lowest for the posterior quadrant. The calculated critical values of J-integral for the radial cracks, ranging from $983 \mathrm{~N} / \mathrm{m}$ to $2664 \mathrm{~N} / \mathrm{m}$, were significantly lower compared with those for specimens having transverse cracks. Significant differences were found between anterior to lateral ( $p=$ $0.0026)$, medial to lateral $(p=0.0032)$ and posterior to lateral $(p=0.0005)$ quadrants. Finally, for specimens with cracks extending along the direction parallel to osteons (longitudinal cracks), the critical J-integral values were comparable with those for radial cracks, and their highest value was found for the lateral quadrant whereas the lowest was in anterior specimens. Statistically significant differences in this case were found between anterior to medial $(p=0.0279)$, anterior to lateral $(p=0.006)$ and posterior to lateral $(p=0.01)$ quadrants. Generally, comparing the date for all four cortices, higher fracture toughness was demonstrated by specimens cut from the medial and lateral quadrants. The disparity between these two groups ranges from as low as $18.3 \%$ up to $171 \%$.

This non-uniform fracture resistance across different cortices of the bovine femur implies that the variation of microstructure has a great impact on the localized fracture toughness values. Optical-microscopy images presented in Fig. 4 demonstrate distinct features of microstructure with respect to anatomic cortices. Anterior and posterior quadrants are predominantly occupied by primary and secondary osteons, respectively, whereas medial and lateral quadrants have a mixture of both primary and secondary osteons together with a large proportion of interstitial matrix. Previous research [20, 24] showed that a change in the volume fraction of constituents at microstructure level largely affected the local material properties, such as elastic modulus, yield stress, ultimate strength etc., which, in turn, influenced fracture properties. The effect of microstructural orientation also has an important effect on anisotropy of fracture-toughness values. Higher resistance to fracture was found where the cracks propagated perpendicular to osteons orientation, while lower resistance when cracks extended parallel to osteons direction. The anisotropy ratios (calculated as ratios of respective values of $J_{c}$ ) between transversely-orientated cracks and longitudinally- or radially orientated cracks are presented in Table 3. Apparently, the anisotropy ratios also varies for different cortices ranging from 2.13 to 4.36 , with the lowest ratio found for the lateral quadrant and the highest ratio for the anterior quadrant. 


\subsection{SEM studies}

Fracture surfaces were analysed for all the tests using scanning electron microscopy. The results obtained for different crack-extension directions and cortex positions are grouped in Fig. 5. A dissimilar character of roughness of fracture surfaces was evidenced among the four cortex positions; it was an indication of a variety of fracture toughening mechanisms acting in different cortex positions. The transition of the underlying microstructure from one type to another could be the reason for these differences. As shown in Fig. 5, the fracture surfaces from the anterior and posterior quadrants are relatively smoother compared with those for the medial and lateral quadrants. Empirical evidence [25] suggests that the surface roughness is associated with the amount of energy required to generate the fracture surface: lower levels of fracture energy indicate smoother fracture surface.

Additionally, a combination of microstructural changes and different crack-extension directions triggered complicated toughening mechanisms, which, in turn, were reflected in different fracture-toughness values and levels of surface roughness. Generally, for the longitudinal fracture specimens, with crack fronts propagating along the direction parallel to the axis of osteons, the fracture toughening mechanism was dominated by uncracked-ligament bridging during the process of osteons splitting, rupture, interface failure and fibre delamination (see Figs. $6 \mathrm{~L}$ _a, $\mathrm{L}$ b). Similarly, for cracks propagating to the radial direction, the toughening mechanism was still governed by uncracked-ligament bridging as a result of osteon splitting or fibre delamination. However, a slight difference in this case was the existence of interface areas or empty spaces such as cement line or Haversian canals that had a larger contribution towards cracks arresting at these regions [15]. As a result, twists and kinks of osteons were observed in our analysis (see Fig. 6 R_a, $\left.R \_b\right)$. In contrast to the previous two cases, cracks growing along the transverse direction required a larger traction force for the crack front to penetrate and cross the osteons as longitudinal strength of osteons was much higher than transverse one. Cracks were therefore more likely to be deflected due to imperfections and heterogeneity of the microstructure or complete pull outs of osteons (see Fig. 6 T_a). Consequently, higher values of fracture toughness were obtained and rougher crack surfaces were observed. In the elastic-plastic fracture regime, the tensional field at the back of the crack tip also promoted a multi-scale 
bridging effect through shear sliding between interface regions at different levels (see Fig. 6c).

\subsection{Numerical simulations}

The simulation part of the study was focused on the crack initiation and propagation processes in the cortical bone specimens under different loading configurations. The simulations were performed at quasi-static conditions using the Abaqus/implicit solver at a constant loading rate until complete specimen's fracture. The employed damage evolution criterion was based on fracture energy (per unit area) calculated using the obtained experimental results. Results of finite-element simulations are compared with the experimental data in Fig. 7 for different cortices and crack orientations; this comparison shows very good agreement for force-displacement curves. The developed finite-element models successfully reproduced the variability of material responses across four cortices for both longitudinal and transverse crack directions. The results indicate that the fracture-toughness values are largely affected by the local anisotropic material properties linked to the variation of the microstructure [24]. The models also predicted an early-stage damage initiation (Fig .7, horizontal dotted lines), followed by a non-linear progressive damageevolution process. By using a surface-based cohesive traction criterion based on the experiment result, these complex non-linear damage propagation processes were captured reasonably well. Both initial curvature of the graphs and the peak-force levels were determined very close to the obtained experiment results. It was also observed that damage initiation for transverse-crack specimens form the medial quadrant is lower than for longitudinal-crack specimens. The lower damage initiation combined with a higher ultimate fracture force indicates the existence of a strong toughening mechanism for medial transverse0crack specimens (Fig. 7). On the other hand, a high damage-initiation load with a low peak force in longitudinal crack specimens from the anterior quadrant is an indication of a weak toughening mechanism.

\section{Discussion}

The experimental study of the deformation and fracture processes in specimens of bovine femoral cortical bone demonstrated non-uniformity and anisotropy of fracture toughness across varies cortex positions and for different crack orientations. The 
calculated critical values of J-integral range from $983 \mathrm{~N} / \mathrm{m}$ to $5661 \mathrm{~N} / \mathrm{m}$. That is in good agreement with the literature data [26]. This wide spectrum of fracturetoughness values could be interpreted as a result of the material anisotropy due to the microstructure orientation as well as changes in the character of distribution of microstructural constituents at varies anatomic positions. Large anisotropy ratios of the material properties for three perpendicular loading axes lead to significantly higher fracture resistance of transverse-crack specimens than that of longitudinaland radial-crack specimens (Fig. 8 a). Changes in the microstructure between cortex positions result in different levels of fracture toughness at different cortices (i.e. nonuniform distribution of this parameter of a bone's cross-section). Due to a natural loading regime exerted by animal's weight and muscle forces, long bones are normally exposed to combined loading conditions that are spatially non-uniform. As it is well known from literature, bone is a dynamic tissue that reacts to mechanical loading by adapting its shape, internal microstructure and material properties to meet external loading environment [25]. The differences in value of fracture toughness (critical J-integral) could be the outcome of bone adaption to its natural non-uniform loading conditions, where lateral to medial axis may require higher fracture resistance to sustain the loading condition (Fig. 8 b).

From another point of view, the stronger toughening mechanisms at medial and lateral quadrants could be another reason to cause higher fracture toughness. A good proportion of hard and soft materials usually results in a tougher combination as toughening mechanisms at interfaces usually enhance the overall fracture resistance. In other words, combining the stiff interstitial matrix with soft secondary osteons may facilitate formation process of toughening mechanism [27]. Yet, excessive primary or secondary osteons could unbalance the formation process and result in a decline of fracture toughness. Determining the individual fracture toughness of each microstructure constituent or evaluating the natural loading condition of cortical bone will certainly help to gain further understanding of fracture process in the cortical bone tissue. However, they are well beyond the scope of this study and are not discussed here.

\section{Conclusions}


In the presented study, fracture toughness of bovine femoral cortical bone was evaluated, and the effect of its microstructure on fracture-toughness values was examined. Based on the results of this study, the following conclusions were made:

- Bovine femoral cortical bone demonstrated a non-uniform elastic-plastic fracture process for different cortices. The mean values of critical J-integral cover a range, from $983 \mathrm{~N} / \mathrm{m}$ to $5661 \mathrm{~N} / \mathrm{m}$ with the anisotropic ratio ranging from 2 to 4 , depending on the anatomic position and crack-propagation direction.

- Changes in, and anisotropy of, the underlying microstructure play an important role in variability of fracture resistance.

- Fracture-toughening mechanisms varied for different fracture-propagation directions. In longitudinal- and radial-crack specimens they were dominated by uncracked ligaments, while toughness of transverse-crack specimens was governed by crack deflections and multi-scale bridging.

- With the full advantage of the non-linear fracture mechanics, the developed XFEM models successfully reproduced the variability and anisotropy of the non-linear fracture process of cortical bone under three point bending, which confirmed a strong link between fracture toughness values to the localized material properties.

\section{Acknowledgment}

The authors acknowledge the financial support from EPSRC UK (grant no. EP/G048886/1). 


\section{References}

[1] Currey JD. The design of mineralised hard tissues for their mechanical functions. J Exp Biol 1999;202:3285-94.

[2] Fratzl P, Gupta HS, Paschalis EP, Roschger P. Structure and mechanical quality of the collagen-mineral nano-composite in bone. J Mater Chem 2004;14:2115-23.

[3] Ethier CR, Simmons CA. Introductory biomechanics: from cells to organisms. : Cambridge Univ Press, 2007.

[4] Peterlik H, Roschger P, Klaushofer K, Fratzl P. Orientation dependent fracture toughness of lamellar bone. Int J Fract 2006;139:395-405.

[5] Wang X, Puram S. The toughness of cortical bone and its relationship with age. Ann Biomed Eng 2004;32:123-35.

[6] Zioupos P, Currey JD. The extent of microcracking and the morphology of microcracks in damaged bone. J Mater Sci 1994;29:978-86.

[7] Zioupos $P$, Wang X, Currey JD. The accumulation of fatigue microdamage in human cortical bone of two different ages in vitro. Clin Biomech 1996;11:365-75.

[8] Vashishth D, Tanner KE, Bonfield W. Experimental validation of a microcrackingbased toughening mechanism for cortical bone. J Biomech 2003;36:121-4.

[9] Liu D, Weiner S, Daniel Wagner H. Anisotropic mechanical properties of lamellar bone using miniature cantilever bending specimens. J Biomech 1999;32:647-54.

[10] Nalla RK, Kinney JH, Ritchie RO. Mechanistic fracture criteria for the failure of human cortical bone. Nature Mater 2003;2:164-8.

[11] Nalla RK, Kruzic JJ, Ritchie RO. On the origin of the toughness of mineralized tissue: microcracking or crack bridging. Bone 2004;34:790-8.

[12] Nalla RK, Kruzic JJ, Kinney JH, Ritchie RO. Mechanistic aspects of fracture and R-curve behavior in human cortical bone. Biomaterials 2005;26:217-31.

[13] Martin RB, Boardman DL. The effects of collagen fiber orientation, porosity, density, and mineralization on bovine cortical bone bending properties. J Biomech 1993;26:1047-54.

[14] Behiri JC, Bonfield W. Orientation dependence of the fracture mechanics of cortical bone. J Biomech 1989;22:863-72.

[15] Ural A, Vashishth D. Cohesive finite element modeling of age-related toughness loss in human cortical bone. J Biomech 2006;39:2974-82. 
[16] Morais JJL, De Moura MFSF, Pereira FAM, Xavier J, Dourado N, Dias MIR Azevedo JM. The double cantilever beam test applied to mode I fracture characterization of cortical bone tissue. J Mech Behav Biomed Mater 2010;3:446-53.

[17] Ural A, Zioupos P, Buchanan D, Vashishth D. The effect of strain rate on fracture toughness of human cortical bone: A finite element study. J Mech Behav Biomed Mater 2011;4:1021-32.

[18] Liu XC, Qin X, Du Z. Bone fracture analysis using the extended finite element method (xfem) with abaqus. The 34th Annual Meeting of the American Society of Biomechanics 2010.

[19] British Standards Institute. Fracture mechanics toughness tests. Method for determination of Klc, critical CTOD and critical $\mathrm{J}$ values of metallic materials. BS 7448-1 1999.

[20] Abdel-Wahab AA, Alam K, Silberschmidt VV. Analysis of anisotropic viscoelastoplastic properties of cortical bone tissues. J Mech Behav Biomed Mater 2010;4:807-20.

[21] Pithioux M, Lasaygues $P$, Chabrand $P$. An alternative ultrasonic method for measuring the elastic properties of cortical bone. J Biomech 2002;35:961-8.

[22] Bayraktar HH, Morgan EF, Niebur GL, Morris GE, Wong EK, Keaveny TM. Comparison of the elastic and yield properties of human femoral trabecular and cortical bone tissue. J Biomech 2004;37:27-35.

[23] Pattin CA, Caler WE, Carter DR. Cyclic mechanical property degradation during fatigue loading of cortical bone. J Biomech 1996;29:69-79.

[24] Li S, Demirci E, Silberschmidt VV. Variability and anisotropy of mechanical behavior of cortical bone in tension and compression. J Mech Behav Biomed Mater 2012; under review.

[25] Currey JD. The structure and mechanics of bone. J Mater Sci 2011;41:41-54.

[26] Ritchie RO, Kinney JH, Kruzic JJ, Nalla RK. A fracture mechanics and mechanistic approach to the failure of cortical bone. Fatigue Fract Eng M 2005;28:345-71.

[27] Guo X, Liang L, Goldstein SA. Micromechanics of osteonal cortical bone fracture. J Biomech Eng 1998;120:112-7. 
Nomenclatures

*_L

*_R

*_T

a

A_*

$\mathrm{a}_{0}$

B

CTOD

CZE

DCB

$\mathbf{E}_{1}$

$\mathbf{E}_{2}$

EPFM

FEM

$\mathbf{G}_{12}$

$\mathrm{K}_{\text {Ic }}$

$\mathrm{L}$

L_*

LSD

LVDT

M_*

$p$

$\mathrm{P}_{-} *$

$\mathrm{S}$

SD

SEM

SENB

$\mathrm{U}_{\mathrm{p}}$

VCCT

W

X-FEM

$\alpha$

$v$

$\sigma_{Y S}$ longitudinal crack propagation direction

radial crack propagation direction

transverse crack propagation direction

crack length

anterior quadrant

average initial crack length

thickness

crack tip opening displacement

cohesive zone element

double-cantilever beam

Young's modulus for longitudinal direction (osteons direction)

Young's modulus for transverse direction (perpendicular to osteons direction)

elastic-plastic fracture mechanics

finite-element models

shear modulus

critical stress intensity factor

total length of specimen

lateral quadrant

Least Significant Difference test

Linear variable differential transducer

medial quadrant

probability value

Posterior quadrant

span

standard deviation

scanning electron microscopy

single-edge-notch bending

plastic component of area under plot of force versus specimen

virtual crack closure technique

width

extended finite-element method

significance level

Poisson's ratio

yield stress 
Figure 1 (a) Schematic illustration of bovine femur; (b) cortex positions in cortical bone; (c) specimens with different crack propagation directions: longitudinal, transverse and radial. Arrows show crack propagation directions.

Figure 2 Three-point-bending setup with single-edge-notch cortical bone specimen mounted on Instron 3345 machine and LVDT.

Figure 3 (a) Schematic of used three-point bending setup, distance between fixed grips is $\mathrm{S}=4 \mathrm{~W}=21.72 \mathrm{~mm}$; (b) mesh used for cortical bone specimen; (c) geometry and dimensions of cortical bone specimens used tests and simulations.

Figure 4 Representative microstructural features of different cortex positions: (a) anterior; (b) medial; (c) posterior; (d) lateral

Figure 5 Scanning-electron-microscopy images of fracture surfaces for various cortex positions and crack propagation directions: A, M, P and L denote anterior, medial, posterior and lateral cortices; _L,_R,_T denote crack propagation directions for longitudinal, radial and transverse directions, respectively; white arrow indicates crack growing direction

Figure 6 Schematic illustrations and SEM images of various toughening mechanisms for longitudinal (a), radial (b) and transverse (c) cracks-growth directions, Labels at the bottom of each image indicate the corresponding magnified areas from Fig. 5.

Figure 7 Comparison of experimental and calculated force-displacement curves: A, M, P and L denote anterior, medial, posterior and lateral specimens;_L, _R, _T denote longitudinal, radial and transverse crack propagation directions; dotted lines indicate damage initiation position.

Figure 8. Illustration of variability of mean critical J-integral values: (a) a bar chart indicates mean and standard deviation (error bars) for different crack-propagation directions; (b) a radar chart indicates fracture toughness along the anatomic positions. 


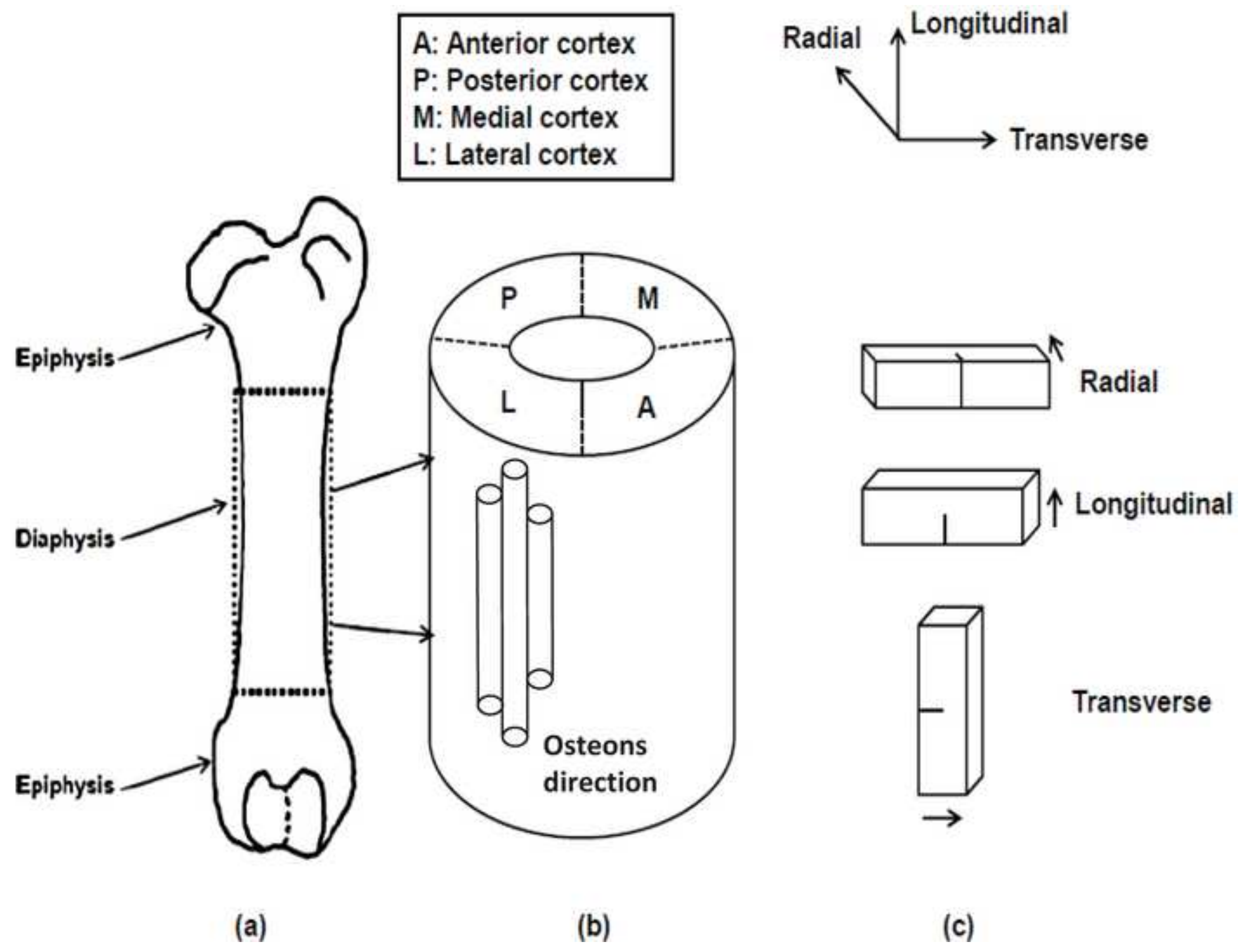


Click here to download high resolution image

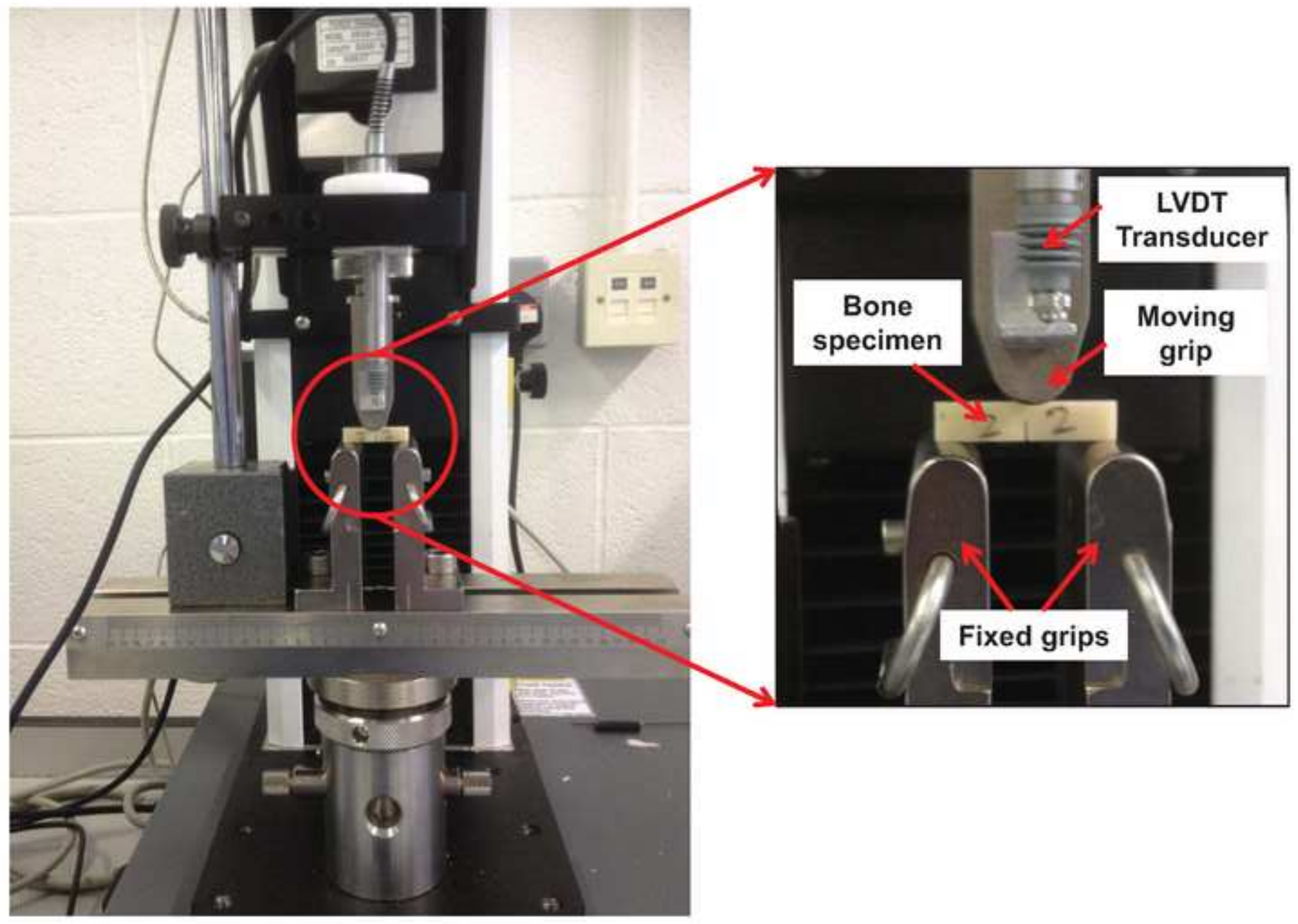




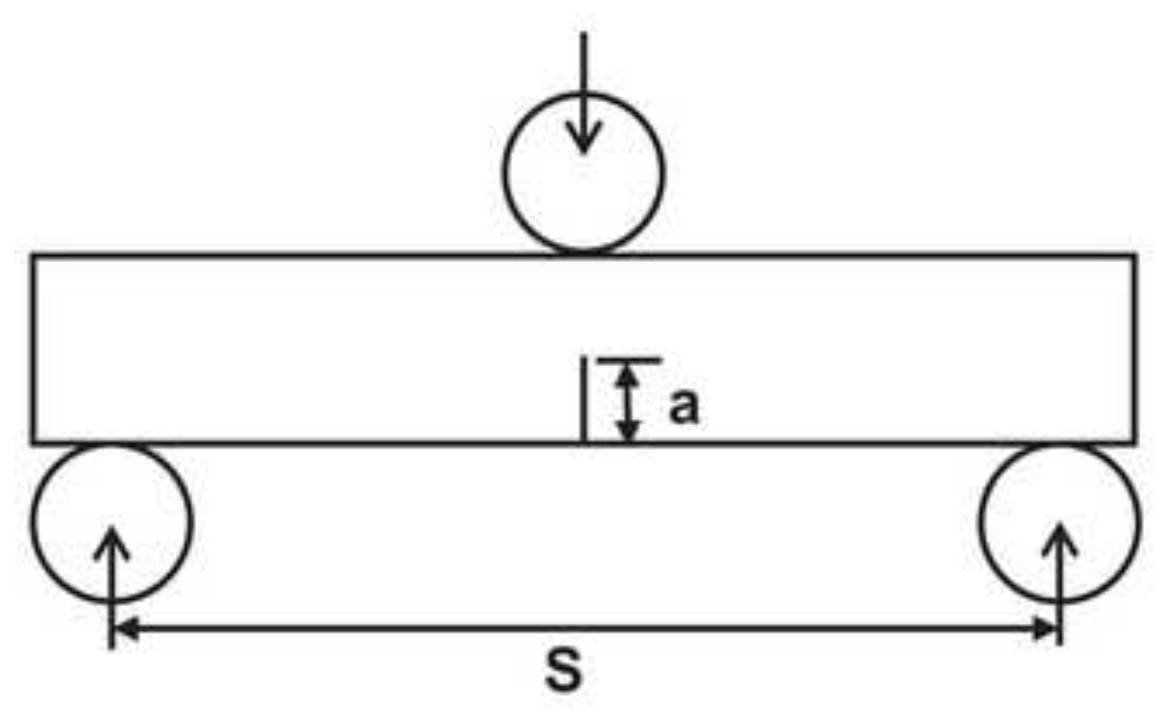

(a)

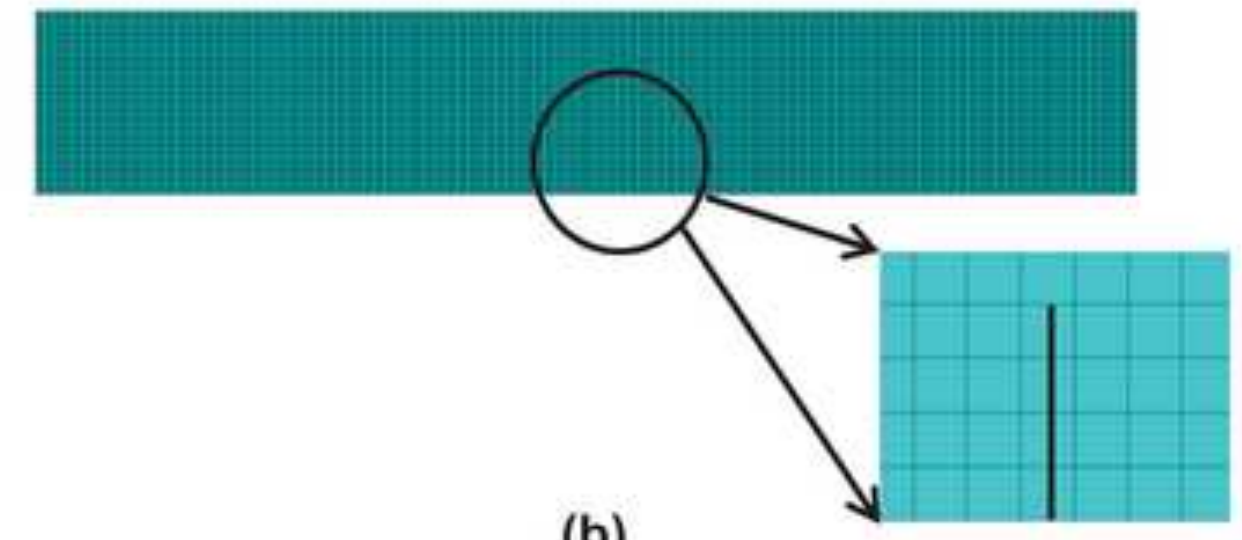

(b)

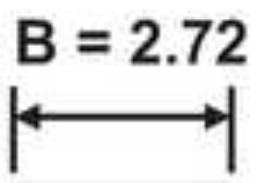

$$
\begin{aligned}
& S=\text { span } \\
& W=\text { width } \\
& B=\text { thickness } \\
& a=\text { crack length }
\end{aligned}
$$

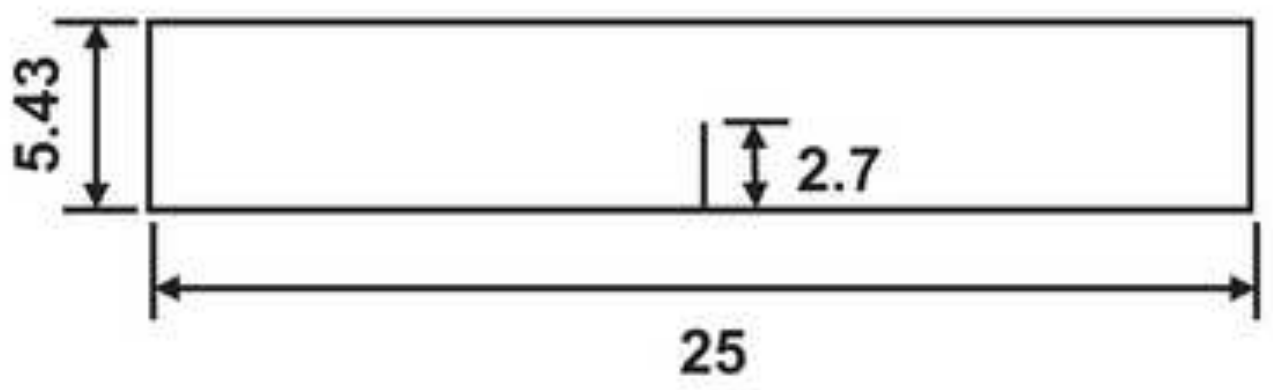

Dimensions in $\mathrm{mm}$ 


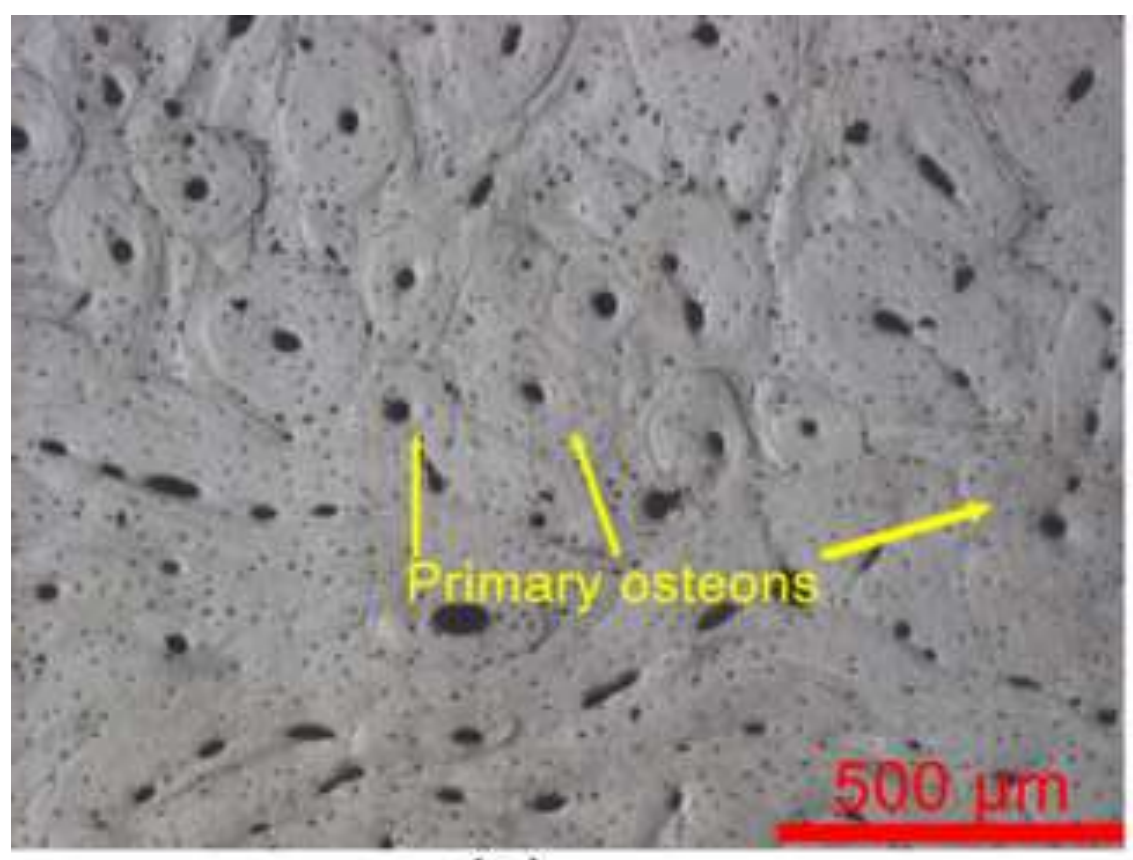

(a)

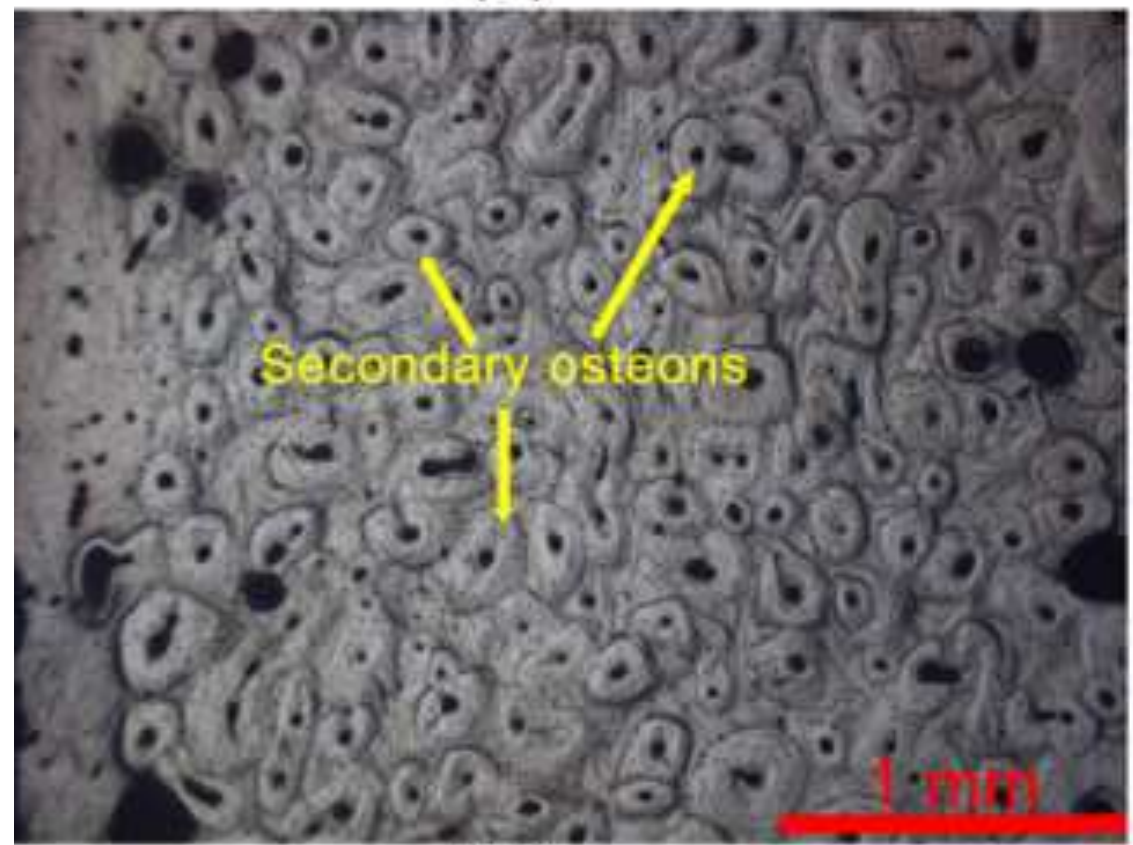

(c)

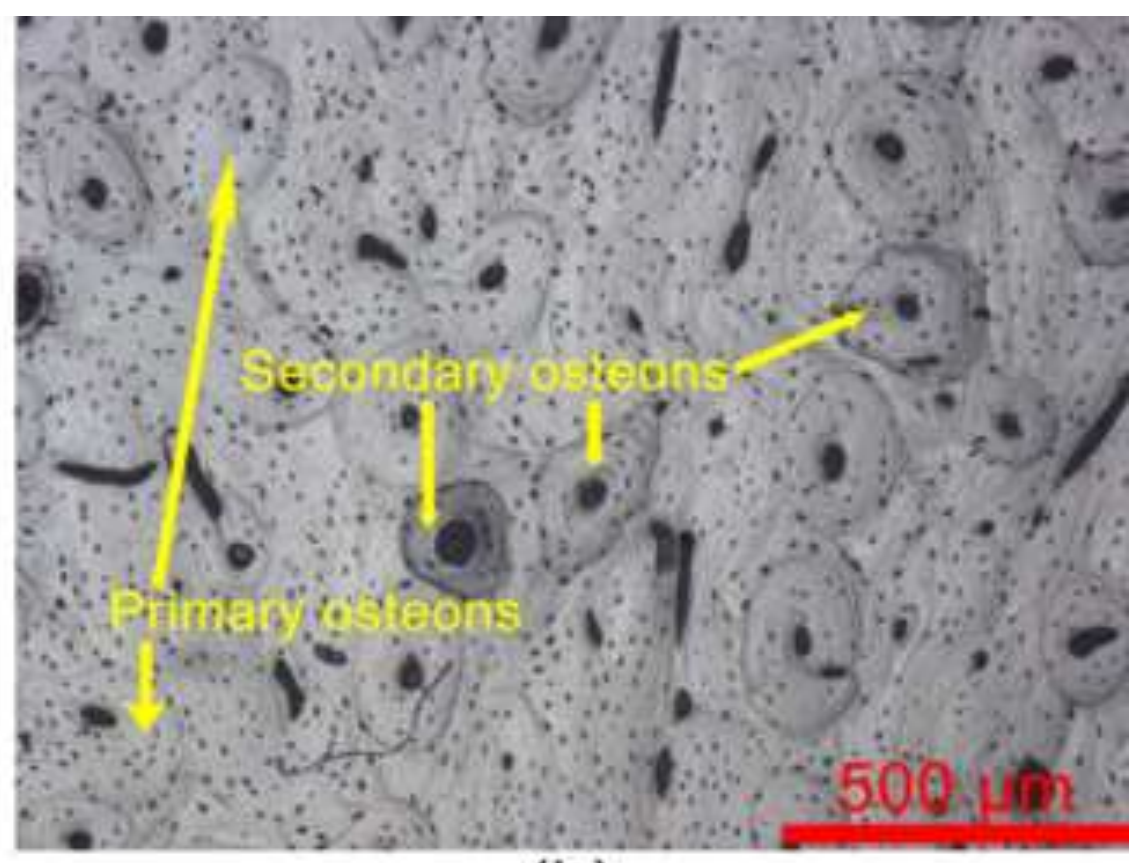

(b)

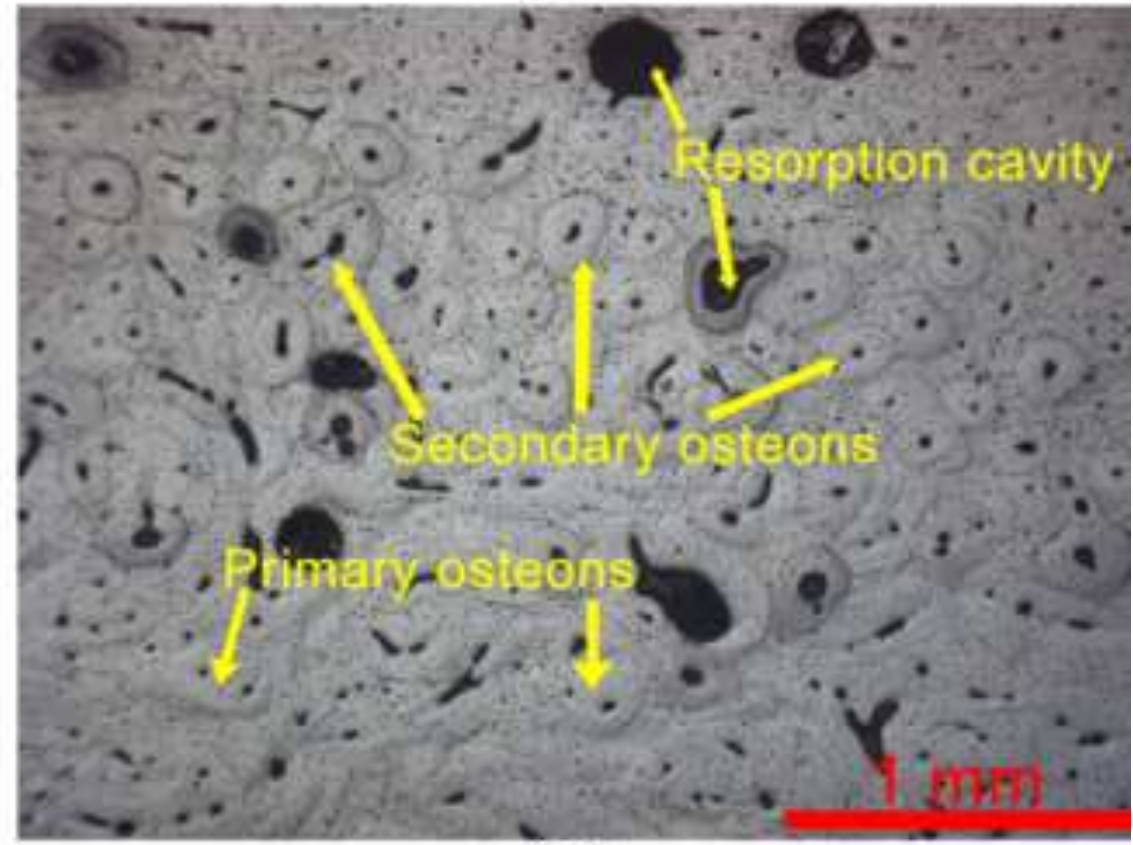

(d) 

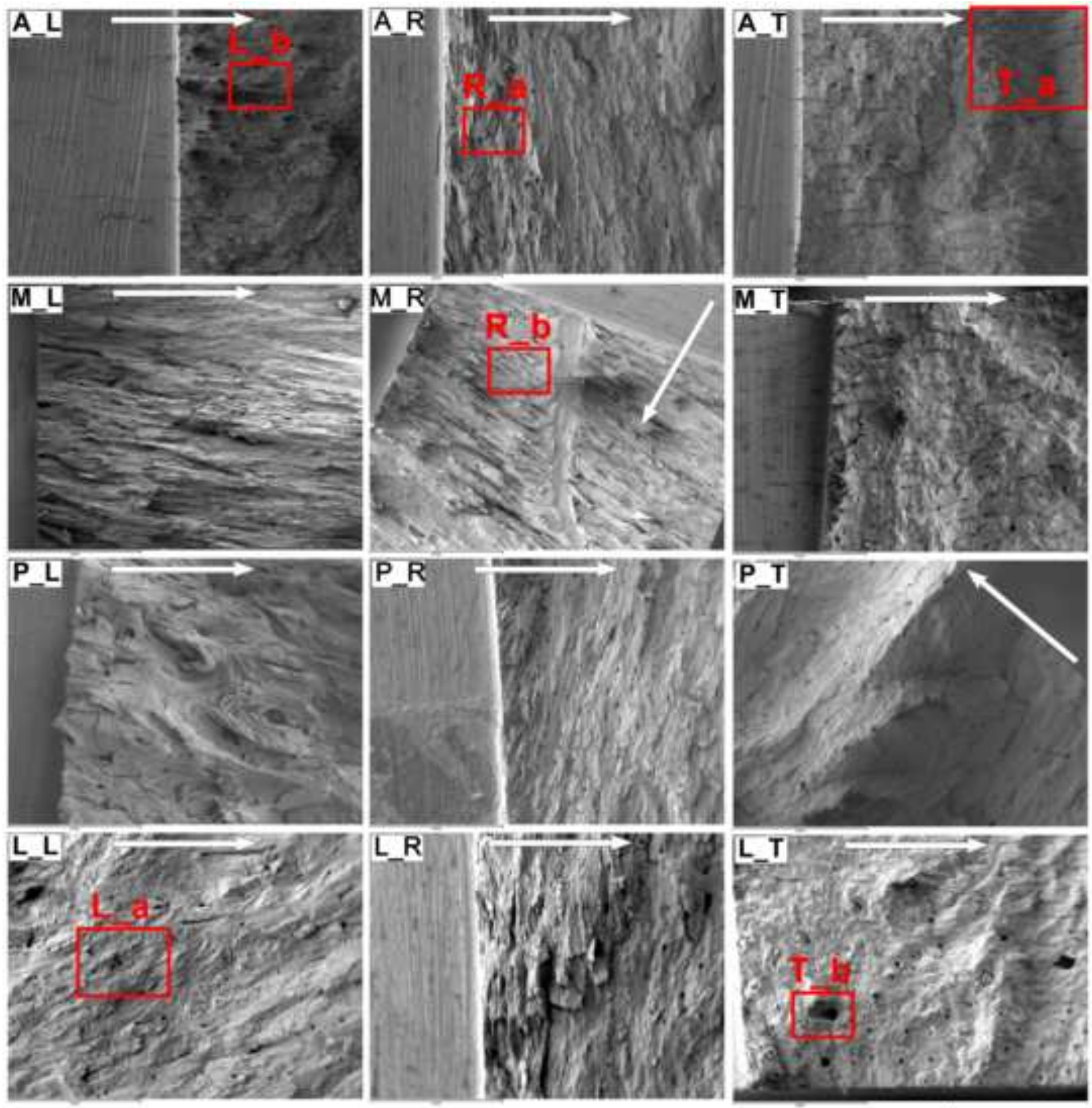
Click here to download high resolution image
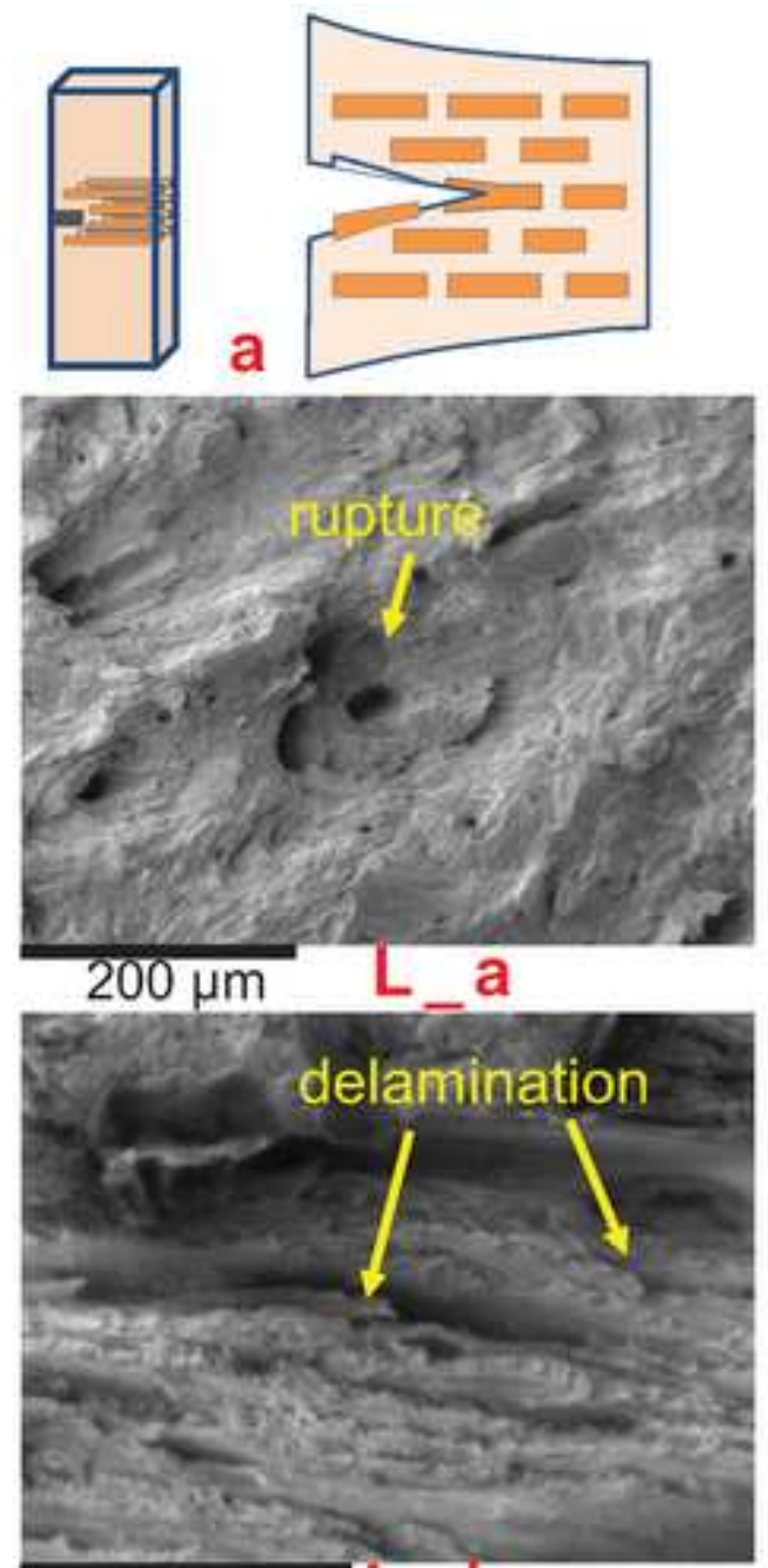

$40 \mu \mathrm{m} \mathrm{L}_{-} \mathrm{b}$

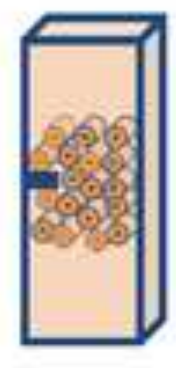

b

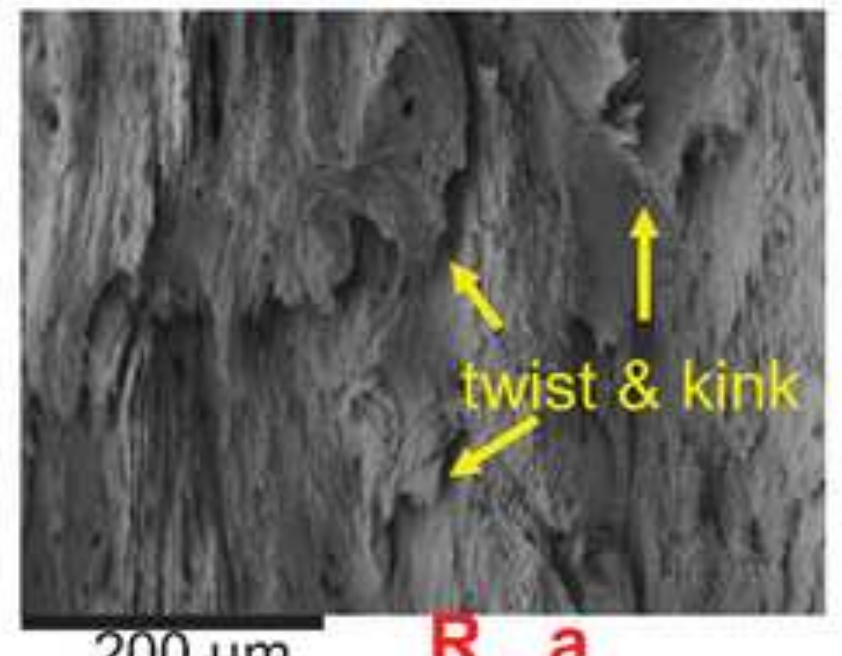

$200 \mu \mathrm{m}$

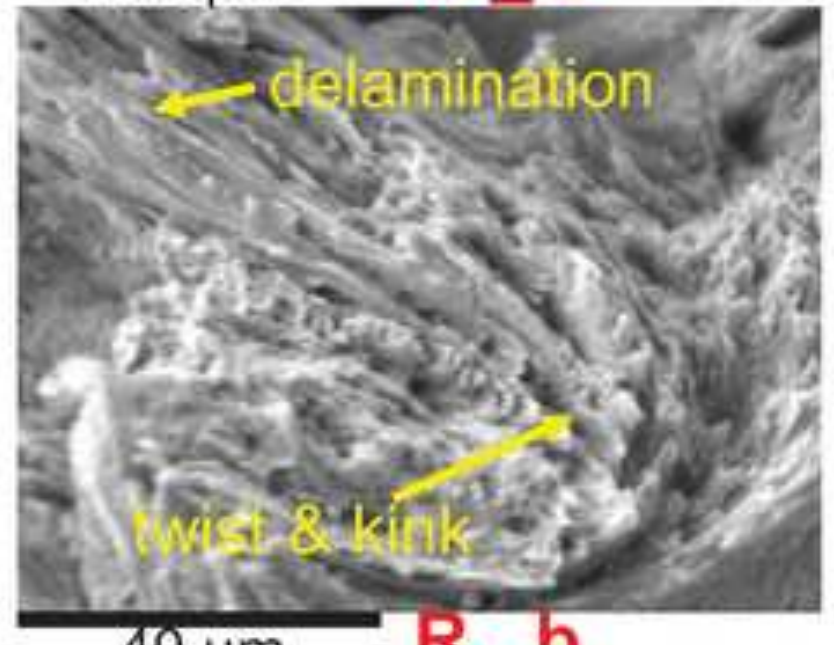

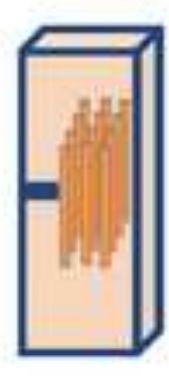
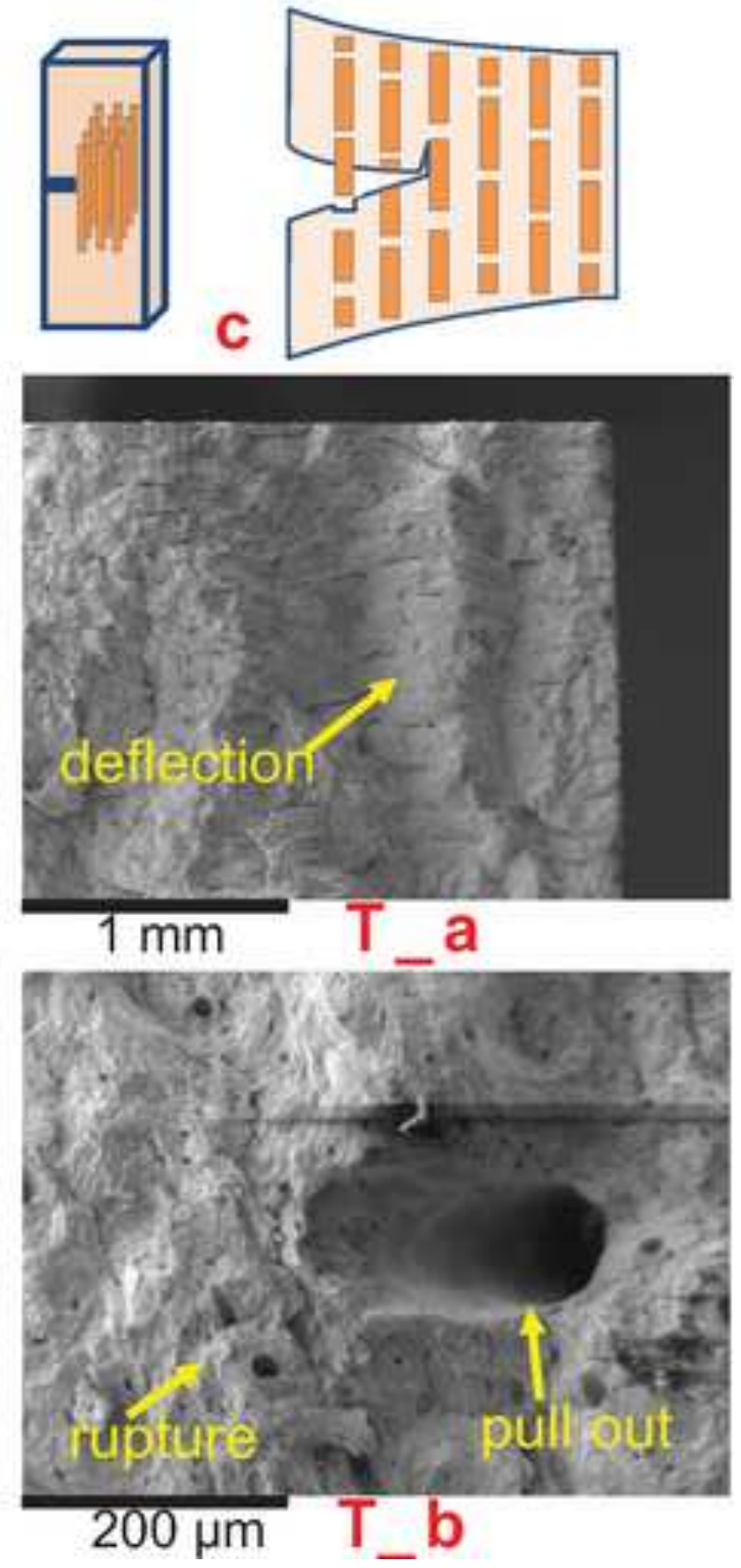

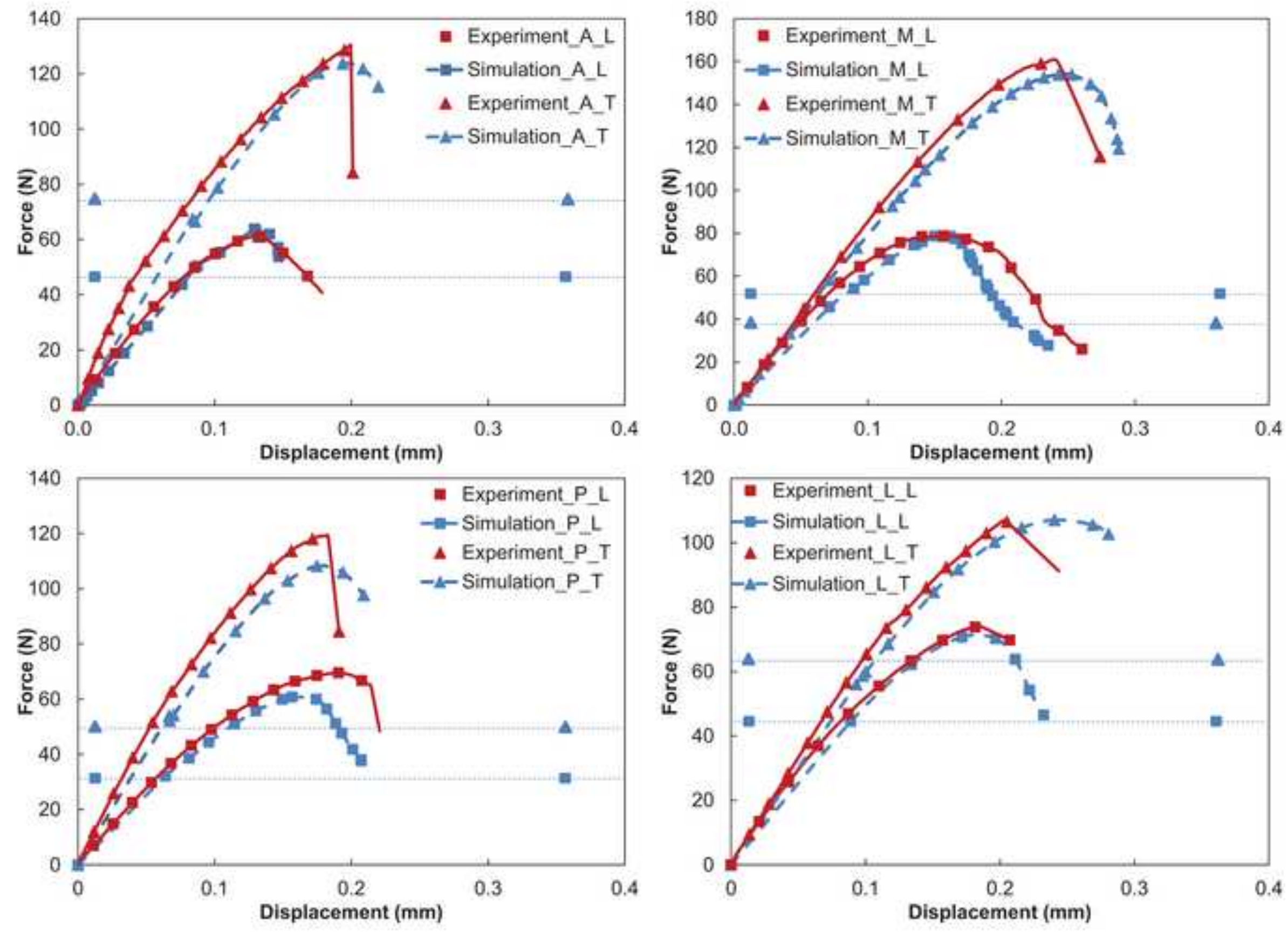


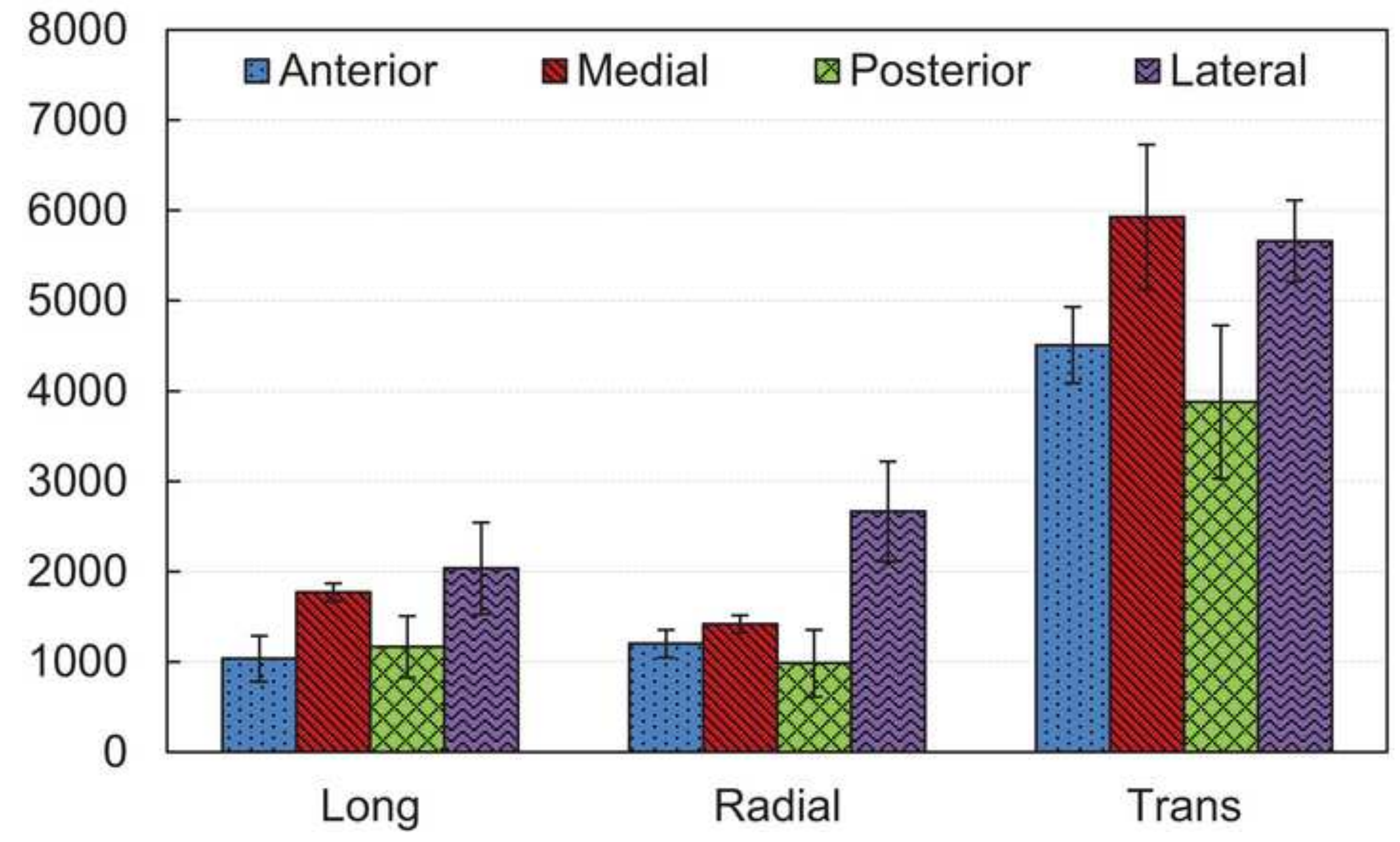




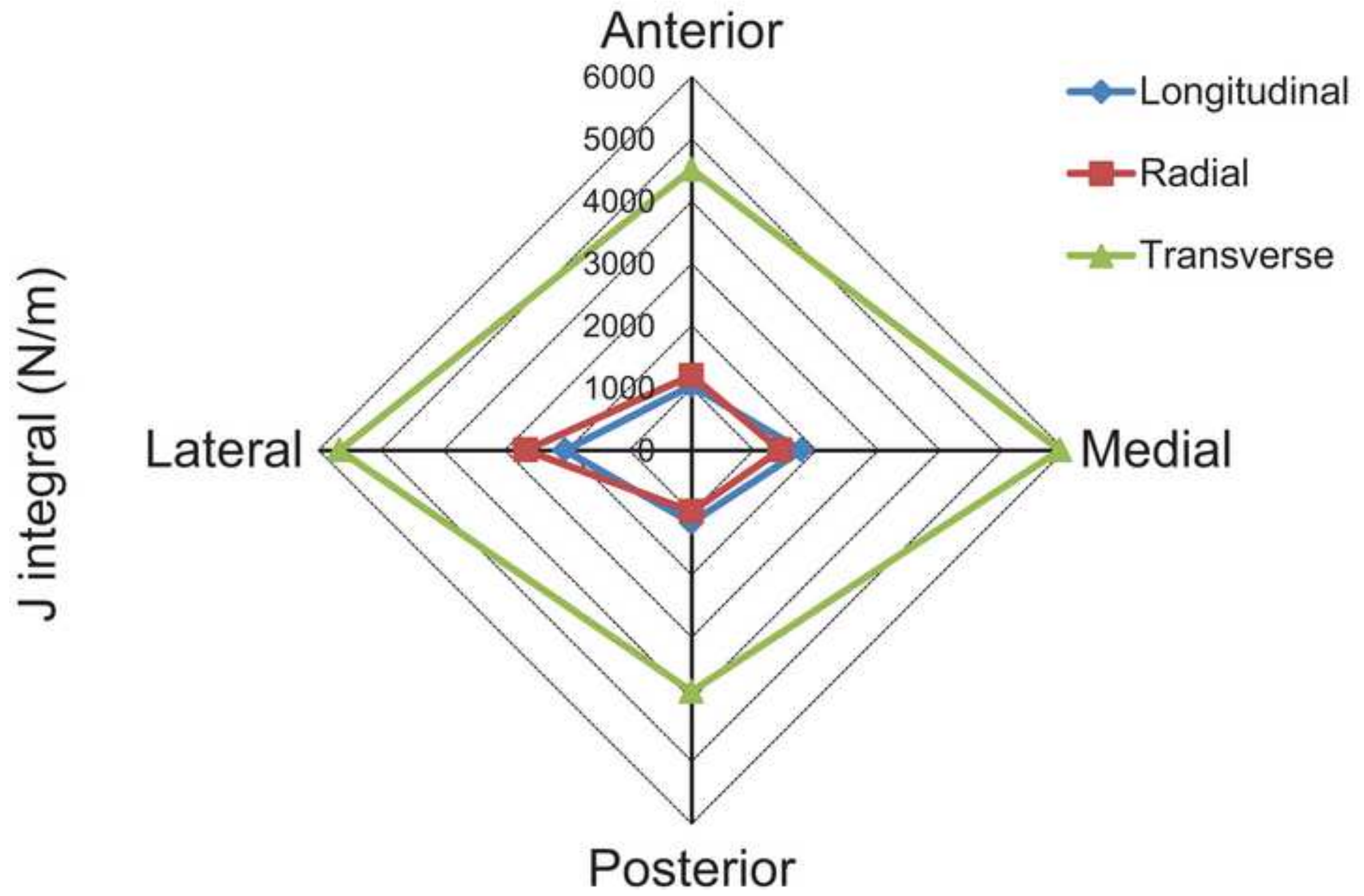


Table 1 Transverse Isotropic material properties [20, 21] used in FE models (subscripts denote axial orientation: 1 - longitudinal; 2 - transverse)

Table 2 Average and standard deviation of critical values of J-integral (in N/m) for all cortex positions and crack growth directions

Table 3 Anisotropy ratios of fracture toughness values compared for different crack growth directions and various cortex positions 


\begin{tabular}{ccccc}
\hline & $\begin{array}{c}\mathbf{E}_{\mathbf{1}}[20], \\
\mathbf{G P a}\end{array}$ & $\begin{array}{c}\mathbf{E}_{\mathbf{2}}[20], \\
\mathbf{G P a}\end{array}$ & $\mathbf{v}[21]$ & $\begin{array}{c}\mathbf{G}_{\mathbf{1 2}}[20], \\
\mathbf{G P a}\end{array}$ \\
\hline Anterior & 23.15 & 13.20 & 0.29 & \\
Posterior & 18.00 & 10.20 & 0.29 & \\
Medial & 21.13 & 14.67 & 0.29 & 3.00 \\
Lateral & 15.14 & 11.18 & 0.29 & \\
\hline
\end{tabular}




\begin{tabular}{cccccrccc}
\hline & \multicolumn{2}{c}{ Anterior } & \multicolumn{2}{c}{ Medial } & \multicolumn{2}{c}{ Posterior } & \multicolumn{2}{c}{ Lateral } \\
& Mean & SD & Mean & \multicolumn{1}{c}{ SD } & \multicolumn{1}{c}{ Mean } & \multicolumn{1}{c}{ SD } & Mean & SD \\
\hline Long & 1033.9 & \pm 254.5 & 1768.5 & \pm 98.8 & 1165.7 & \pm 340.1 & 2034.3 & \pm 509.9 \\
Radial & 1199.1 & \pm 153.1 & 1418.2 & \pm 97.2 & 983.0 & \pm 369.5 & 2664.2 & \pm 554.4 \\
Trans & 4509.1 & \pm 422.1 & 5925.5 & \pm 802.9 & 3876.7 & \pm 847.3 & 5661.6 & \pm 452.7 \\
\hline
\end{tabular}


Table 3

\begin{tabular}{ccccc}
\hline & Anterior & Medial & Posterior & Lateral \\
\hline Transverse/Longitudinal & 4.36 & 3.35 & 3.33 & 2.78 \\
Transverse/Radial & 3.76 & 4.18 & 3.94 & 2.13 \\
\hline
\end{tabular}

